\title{
Comparison between Fuzzy Logic Controller (FLC) and Fractional Order Proportional Integral Derivative (FOPID) Controller on Water Level and Steam Temperature of Steam Drum Boiler
}

\author{
Zainullah Zuhri, Mardlijah, and Didik Khusnul Arif
}

\begin{abstract}
Steam drum boiler is an important component of boiler on electric steam power plant which is useful to obtain steam. The obtained steam makes turbine spin. In order to obtain maximal result for the steam power plant (PLTU) 1-2 PT PJB UP Gresik, the water level of steam drum boiler must be $0.7625 \mathrm{~m}$ and the temperature of steam drum boiler must be $786 \mathrm{~K}$. Thus, it needs some controller to keep the position of water level and the temperature stable. In this problem, we compare two controllers FLC and FOPID. It can be concluded that FLC works better than FOPID controller. Nevertheless, FOPID controller has faster response time than FLC, i.e. no overshoot and more robust when disturbance is present on the system.
\end{abstract}

Index Terms - Steam drum boiler, water level, steam temperature, Fractional Order PID controller, Fuzzy Logic Controller.

\section{INTRODUCTION}

$\mathbf{S}$ TEAM Power Plan is power plant using steam to make turbine spin which drives generator. There are some important components on steam power plant such as boiler. In the boiler, there is a part named steam drum boiler, as steam spinning turbine producer. The steam produced must satisfy the standard, where the water level on the steam drum boiler must be in the Normal Water Level (NWL) at 0.7625 meters [1]. If water level is more than NWL, then steam will contain water and will make the turbine broken. On the other hand, if water level is less than NWL, then steam produced is too dried and have the potential to burst. It is also necessary to keep steam temperature at set point $786 \mathrm{~K}$. If the temperature is more than the standard temperature, then steam produced is too dried so that makes turbine and steam drum boiler will be dangerous. On the other hand, if the temperature is less than the standard temperature, then the steam produced contains water causing corrosion on turbine. Hence, its water level and its temperature controller is needed.

In the previous research, FOPID controller worked better than PID and Discrete FOPID controller [1]. FOPID controller contains 2 extra parameters compared to PID Controller: an integrator and a derivative order to improve the performance of PID Controller in a system. One of other controllers is Fuzzy

Manuscript received January 25, 2018; accepted July 27, 2018.

The authors are with the Department of Mathematics, Faculty of Mathematics, Computing, and Data Sciences, Institut Teknologi Sepuluh Nopember, Surabaya, Indonesia. E-mails: zainullah. zuhriegmail . com, $\{$ mardlijah, didik\}@matematika.its.ac.id
Logic Controller, which is simpler, i.e. the decision is similar to human reasoning by interpreting data and giving the best solution [2]. Application of Fuzzy Logic Controller on angular velocity generator control system that the generator can work at approximately settling time 39.4816 seconds and almost has no overshoot. From other controllers, it needs to be done more studying to get better understanding about controller performance which is described above [3]. From this study, we describe 2 different controllers on steam drum boiler. This study is hoped to give a contribution to improve the study about other controllers and as more objective recommendation about the best controller when implemented on steam drum boiler later. By comparing Fuzzy Logic Controller (FLC) and FOPID controller through simulations, we can look for the performance of both controllers. The result was analyzed and was studied in Analysis and Simulation. Then, we can conclude the weakness and strength of each controller. Finally, we conclude the best controller in controlling water level and temperature of steam drum boiler.

\section{Models AND PRELIMINARIES}

This section contains the model of steam drum boiler system, Fuzzy Logic Controller and FOPID controller.

\section{A. Steam Drum Boiler System}

Steam drum boiler is a part of boiler changing water into steam and spinning steam turbine which drives an electrical generator. The drum saves the water that will leave to a burner. The water level and temperature must be in stable conditions, where the water should be in normal water level (NWL) of 0.7625 and steam is in temperature $786 \mathrm{~K}$, the value of two variables (water level and temperature) is obtained from the PLTU system. The water level can be controlled by control valve and temperature can be controlled by a burner. To achieve mathematical model of water level and steam temperature in steam drum boiler as the following [1]

$$
\begin{gathered}
A \frac{d h}{d t}=F_{i} n-k w \sqrt{h} \\
A h \frac{d T}{d t}=F_{i n}\left(T_{i} n-T\right)+\frac{Q}{p C_{p}}
\end{gathered}
$$



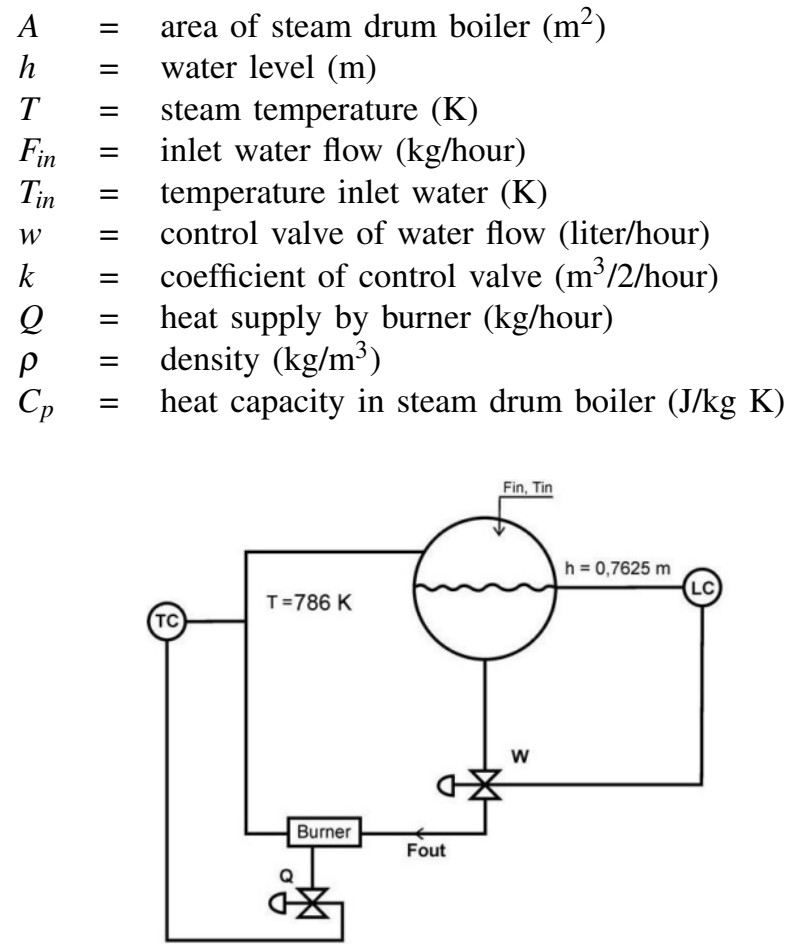

Fig. 1. Steam drum boiler.

By applying the linearization process to mathematical model of water level and steam temperature, we obtained the following transfer function:

$$
\begin{gathered}
h(s)=\frac{\frac{2 \hat{h}}{\hat{w}}}{\left(\frac{2 A \sqrt{\hat{h}}}{k \hat{w}}\right) s+1} w(s) \\
T(s)=\frac{\frac{1}{F_{\text {in }} \hat{h}}\left(F_{\text {in }}\left(T_{\text {in }}-\hat{T}\right)+\frac{\hat{Q}}{\rho C_{\rho}}\right)}{\left(\frac{A \hat{h} s+1}{F \text { in }}\right)+1} h(s)+\frac{\frac{1}{F_{\text {in }} \rho C_{\rho}}}{\left(\frac{A \hat{h} s+1}{\text { Fin }}\right)+1} Q(s)
\end{gathered}
$$

where $\hat{h}=0,7625 \mathrm{~m}, \hat{T}=786 \mathrm{~K}, \hat{w}=13,74$ and $\hat{Q}=660 \mathrm{~kg} /$ hour. The changes of water level also affected to the changes of steam temperature in a steam drum boiler. So, the control valve had an impact on their system dynamic of a steam a drum boiler.

Function transfer control valve expressed as a one-order function as follows [1]:

$$
G_{c v}(s)=\frac{w(s)}{M_{c}(s)}=\frac{K_{t o t}}{\tau_{c v} s+1}
$$

$M_{c}=$ control valve input signal $(\mathrm{mA})$

$K_{\text {tot }}=$ gain control valves

$\tau_{c v}=$ time constant control valve (hour)

By seeing the transfer function on (5), then we obtained the transfer function below [1]:

$$
w(s)=\frac{6,25}{1,78498+1} M_{c}(s)
$$

The mathematical models of steam drum boiler are the equation (3), (4) and (6).

\section{B. Fuzzy Logic Controller}

Fuzzy Logic Controller (FLC) is a control methodology that allows the way human describes systems in physical and define strategy for control used. FLC works as follows. First we compute the error that is the difference between output of plants and set point that was numerical data (crisp) and then we convert the error into linguistic variable in fuzzification block. Output of the fuzzifier inside the block of inference is called as FAM (fuzzy associative memory). FAM is a collection of if-then rules. Output of FAM is tuned in defuzzification to generate the crisp value [3].

1) Design of Fuzzy Logic Controller: To build the control system by using FLC, first we determine the error of the water level and temperature system. The following equation can be used to find the error of the water level and temperature system:

$$
e(t)=h_{\text {system }}-h_{\text {set point }}
$$

$e(t) \quad=$ error

$h_{\text {system }}=$ water level of the system

$h_{\text {setpoint }}=$ desired water level of the system

$$
e(t)=T_{\text {system }}-T_{\text {set point }}
$$

$e(t)=$ error

$h_{\text {system }}=$ temperature of the system

$h_{\text {setpoint }}=$ desired temperature of the system

After that we must find first and second derivative of the error $(\dot{e}, \ddot{e})$. Fuzzy set of the water level control system on each input and output of the control system needs boundary.

The membership function used for every input and output variable is triangle. Linguistic variable used for error input is LOW, MEDIUM, and HIGH. Linguistic variable used for $\dot{e}$ input is NEGATIVE, ZERO, and POSITIVE. Linguistic variable used for $\ddot{e}$ input is LOW, MEDIUM, and HIGH. The following is the linguistic rule [3]

$\mathrm{RB}_{1} \quad \mathrm{IF}$ ( $e$ is Low) AND $(\dot{e})$ is Negative) AND ( $\ddot{e}$ is Zero) THEN ( $\mathrm{u}$ is Medium)

$\mathrm{RB}_{2} \quad \mathrm{IF}$ ( $e$ is Low) AND ( $\dot{e}$ )is Zero) AND ( $\ddot{e}$ is Zero) THEN ( $\mathrm{u}$ is Low)

$\mathrm{RB}_{3} \quad \mathrm{IF}$ ( $e$ is Medium) AND ( $\dot{e}$ is Negative) AND ( $\ddot{e}$ is Zero) THEN ( $\mathrm{u}$ is Medium)

$\mathrm{RB}_{4} \quad \mathrm{IF}$ ( $e$ is Medium) AND ( $\dot{e}$ is Negative) AND ( $\ddot{e}$ is Zero) THEN ( $\mathrm{u}$ is High)

$\mathrm{RB}_{5} \mathrm{IF}$ ( $e$ is High) AND ( $\dot{e}$ is Negative) AND ( $\ddot{e}$ is Negative) THEN ( $\mathrm{u}$ is High)

$\mathrm{RB}_{6} \quad \mathrm{IF}$ ( $e$ is High) AND ( $\dot{e}$ is Negative) AND ( $\ddot{e}$ is Zero) THEN ( $\mathrm{u}$ is High)

$\mathrm{RB}_{7} \quad \mathrm{IF}$ ( $e$ is High) AND ( $\dot{e}$ is Zero) AND ( $\ddot{e}$ is Negative) THEN ( $\mathrm{u}$ is High)

$\mathrm{RB}_{8}$ IF ( $e$ is High) AND ( $\dot{e}$ is Positive) AND ( $\ddot{e}$ is Negative) THEN (u is High)

$\mathrm{RB}_{9} \quad \mathrm{IF}$ ( $e$ is High) AND ( $\dot{e}$ is positive) AND ( $\ddot{e}$ is Zero) THEN ( $\mathrm{u}$ is Medium)

The following is the control system block diagram for fuzzy logic control: 


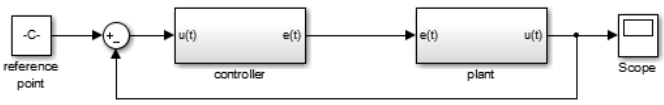

Fig. 2. Continuous Controller Block Diagram

\section{Fractional Order PID Controller}

FOPID controller contains 2 extra parameters compared to PID Controller: an integrator and a derivative order to improve performance of PID Controller in a system [1].

1) Design of Fractional order PID Controller: The transfer function derived from the FOPID controller mathematical model is:

$$
G(s)=\frac{U(s)}{E(s)}=K_{p}+\frac{K_{i}}{s}+K_{d} s
$$

By adding $\lambda$ and $\mu$ parameters, each of them is called order of integral and derivative, respectively. Hence, we obtained the transfer function of FOPID controller [1]:

$$
G_{c}(s)=\frac{U(s)}{E(s)}=K_{p}+\frac{K_{i}}{s^{\lambda}}+K_{d} s^{\mu}
$$

Where $0>\lambda, \mu$.

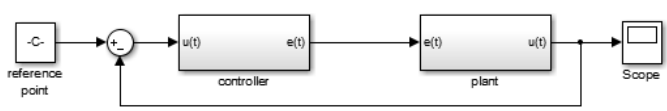

Fig. 3. Continuous Controller Block Diagram

\section{ANALYSIS AND SimUlations}

In this simulation, we compare the performance of FLC and FOPID controller. The aims of this simulation are to study the performance of each controller and decide which controller is more robust against disturbances. The simulation uses parameter values shown below [1]:

TABLE I

PARAMETER OF STEAM DRUM BOILER

\begin{tabular}{|c||c|}
\hline Parameter & Value \\
\hline$F_{\text {in }}$ & $386.54 \mathrm{~kg} / \mathrm{h}$ \\
\hline $\mathrm{A}$ & $1.2561562 \mathrm{~m}^{2} \mathrm{~kg} / \mathrm{h}$ \\
\hline $\mathrm{P}$ & $1000 \mathrm{~kg} / \mathrm{m}^{3}$ \\
\hline $\mathrm{K}$ & $1 \mathrm{~m}^{3} / 2 / \mathrm{h}$ \\
\hline$T_{\text {in }}$ & $796 \mathrm{~K}$ \\
\hline$C_{P}$ & $79.676 \mathrm{j} / \mathrm{mol} \mathrm{K}$ \\
\hline
\end{tabular}

Firstly, we simulated LFC and FOPID controller on water level subsystem. Then we simulated FOPID controller and FLC on steam temperature subsystem. From this simulation, we analyzed the data so the better controller performance is obtained.

\section{A. Subsystem Water Level And Steam Temperature Control using Fuzzy Logic Controller}

To design control system using fuzzy logic controller, we compute the error $(e)$, first derivative of error $(\dot{e})$, and second derivative of error $(\ddot{e})$. This error was obtained from difference between output of the system and the set point. The error of water level subsystem is [0.4550227 0.7625], $\dot{e}$ is $[-0.20176$ $0]$, and $\ddot{e}$ is [-0.764 0.130234]. The output is [0 2.197].

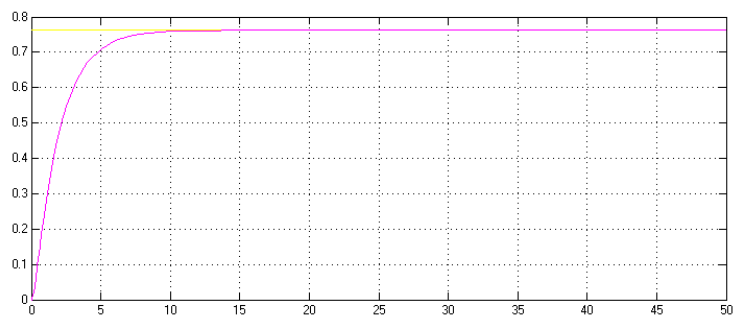

Fig. 4. Response of water level subsystem under FLC

It was obtained that the settling point is 7.7 hours and overshoot is $0 \%$.

The same process was done for temperature subsystem. To design control system using FLC, we compute error $(e)$, first derivative of error $(\dot{e})$, and second derivative of error $(\ddot{e})$. This error was obtained from the difference between output of the system and the set point. The error of temperature subsystem is [776 786], $\dot{e}$ is [-32 1.528e-05], and $\ddot{e}$ is [$7.97 \mathrm{e}+152.097 \mathrm{e}+15]$. The output is $[04.775 \mathrm{e}+10]$.

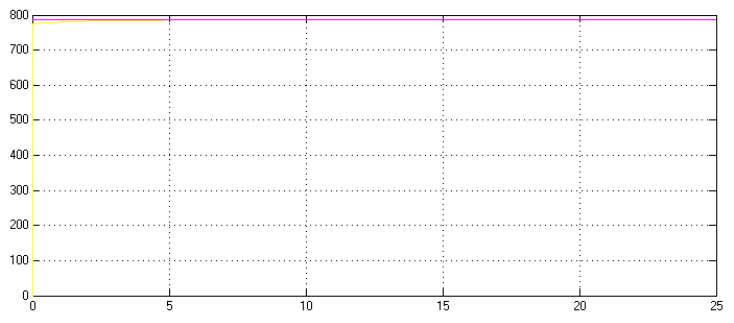

Fig. 5. Response of steam temperature subsystem under FLC

It was obtained that the settling point is 0.02 hours and overshoot is $0 \%$.

\section{B. Subsystem Water Level And Steam Temperature Control by FOPID}

The important thing to design FOPID Controller is to tune parameters $\lambda$ and $\mu$. Tuning is done using a genetic algorithm. The first step is to initialize the initial conditions. Let $0<\mu<2$ and $0<\lambda<2$. By combining $\lambda$ and $\mu$, we can obtain the best performance.

Based on equation (8) we obtain FOPID controller transfer function for water level subsystem in a steam drum boiler as follows:

$$
G_{h F O P I D}(s)=8.4+\frac{8.4}{s^{0} .5}+21 s^{0.8}
$$

By using trial and error method, we obtained the best response with value $\lambda=0,9$ and $\mu=0.8$ so that water level subsystem reached stability in set point by settling time 2.5 hours and overshoot at maximum point by $4.6 \%$. 


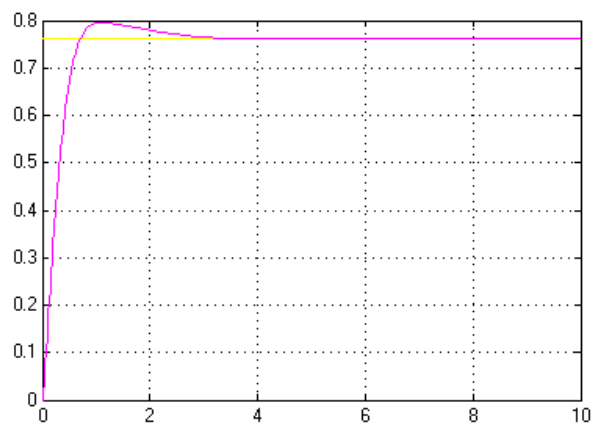

Fig. 6. Response of water level subsystem under FOPID Controller

Based on equation (8), we obtained FOPID controller transfer function for a steam temperature subsystem as follows.

$$
G_{t F O P I D}(s)=6 \times 10^{7}+\frac{7741935483.87097}{s}+116250 s^{0,1}
$$

By using trial and error method, we got the best response

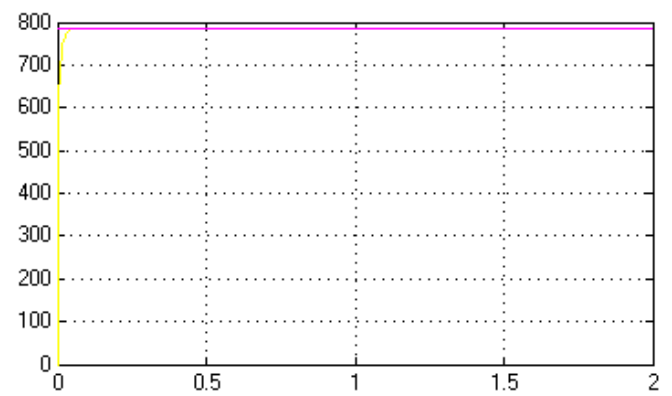

Fig. 7. Response of steam temperature subsystem in a steam drum boiler under FOPID Controller

with value $\lambda=1$ and $\mu=0.1$ so that steam temperature subsystem reaches stability in set point by settling time 0.075 hours without overshoot.

\section{Disturbance-free Case}

In this case, FLC and FOPID controller were simulated without disturbance. We combine simulation result from (A) and (B) so we can see the difference of FLC and FOPID controller performance.

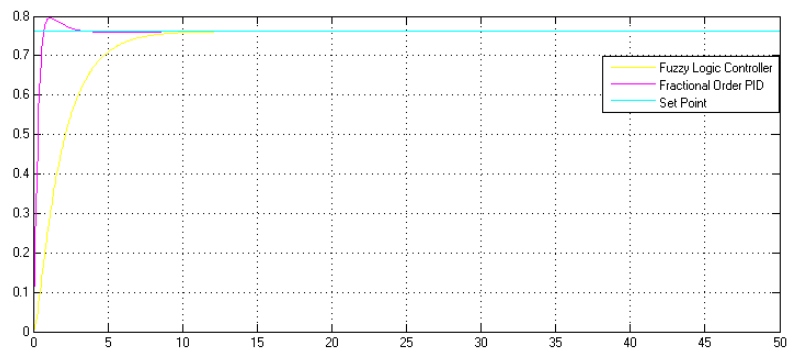

Fig. 8. FLC and FOPID of water level control without disturbance

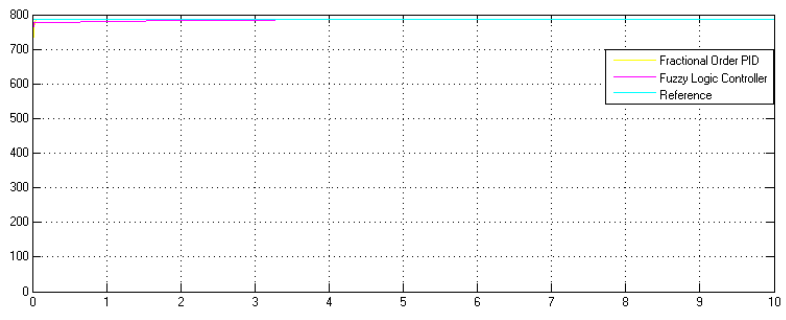

Fig. 9. FLC and FOPID of water level control without disturbance

Based on the result shown in Fig. 8, FOPID controller is faster to reach the set point than FLC. But FLC has better stability because FLC does not have overshoot and FOPID Controller have overshoot at maximum point by $4.6 \%$.

According to the result shown in Fig. 9, FOPID controller is faster to reach the set point than FLC, and there is no overshoot on FOPID controller and FLC.

\section{With Disturbance}

In this case, FLC and FOPID controller were simulated with pulse signal. Pulse signal is a signal appearing at certain time interval. It represents a disturbance from the outside of the control system at time interval. The signal represents the excessive blow down operation [4].

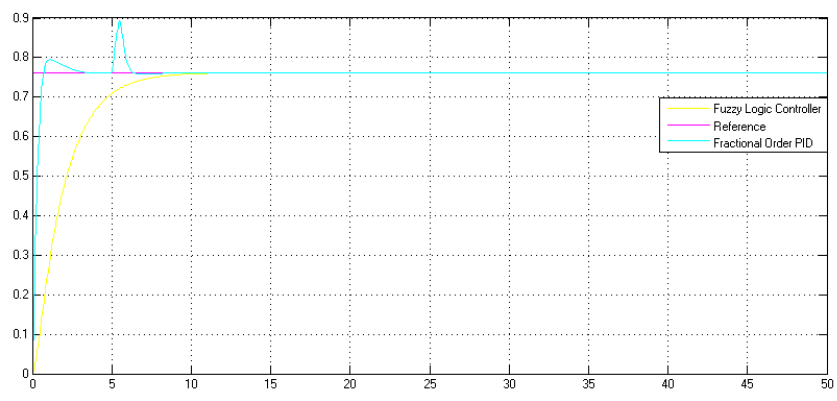

Fig. 10. FLC and FOPID Controller temperature control with square disturbance

In this simulation the pulse signal disturbance was given at 5th hour until 5.5th hour. The result is shown in Fig. 9, FLC is more robust than FOPID Controller. FOPID controller required 6.6 hours to be stable after the disturbance ended up in an overshoot of $17.18 \%$. While, FLC remains stable although there is a slight disruption.

The same proses was conducted for temperature. Simulation for the pulse signal disturbance was given at 5th hour until 5.5th hour. The result is shown in Fig. 9, where FLC is more robust than FOPID controller. FOPID controller required 5.5 hour to be stable after the disturbance finished and there is no overshoot. While, FLC remains stable although there is a small disruption.

\section{CONCLUSIONS}

Based on the work above, it can be concluded that FLC works better than FOPID Controller because only rise time Fractional Order PID Controller (FOPID) has better than 


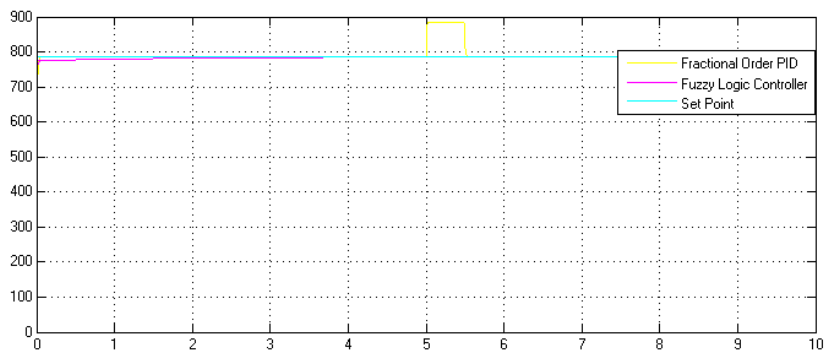

Fig. 11. FLC and FOPID Controller temperature control with square disturbance

Fuzzy Logic Controller (FLC). However, there is an overshot in the system with FOPID Controller, the valve of overshot is $4.6 \%$. While in the system with FLC, there is no overshot. On the other hand, FLC has better stability when the system receives an external disturbance.

So from our comparison, in general FLC is preferable than FOPID. Therefore, Type 2 Fuzzy Logic Controller ought to be preferable than FLC. This case is occurred because Type 2 Fuzzy Logic Controller has preferable ability to surmount indefiniteness. This result can be used as a reference of selecting control method of steam turbine.

\section{REFERENCES}

[1] T. Herlambang, "Desain pengendalian ketinggian air dan temperatur uap pada sistem steam drum boiler dengan metode sliding mode control (SMC)," Tugas Akhir Jurusan Matematika, FMIPA ITS, Surabaya, 2010.

[2] R. Maerani and S. Bakhri, "Perbandingan sistem pengontrolan pid konvensional dengan pengontrolan cmac, fuzzy logic dan ann pada water level pressurizer," SIGMA EPSILON-Buletin Ilmiah Teknologi Keselamatan Reaktor Nuklir, vol. 17, no. 3, 2013.

[3] Supriadi, M. A. Muslim, and R. N. Hasanah, "Analisis sistem kontrol kecepatan putar poros generator dengan menggunakan logika fuzzy," in Proceedings of the 6th Electrical Power, Electronics, Communications, Controls, Informatics International Seminar, 2012, p. D3.

[4] B. Dewantara, "Tinjauan teknis perubahan kinerja steam drum di boiler akibat blowdown pada pltu unit 3 dan 4 (studi kasus di pt pjb up gresik)," B.S. Thesis, Institut Teknologi Sepuluh Nopember, 2010. 